\title{
Analysis of dry-spot behavior in the pressure field of a liquid composite molding process
}

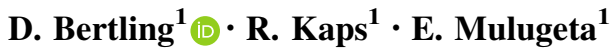

Received: 21 May 2015/Revised: 5 July 2016/Accepted: 22 July 2016/Published online: 31 August 2016

(c) The Author(s) 2016. This article is published with open access at Springerlink.com

\begin{abstract}
Due to industrial automation of liquid composite molding processes and increasing geometrical complexity of composite components, dry-spots from flow front junctions have become increasingly difficult to avoid. The impact and behavior of voids (microscopic or small macroscopic gas entrapments) during preform impregnation is well known, but no attention is given to dry-spots (large macroscopic gas entrapments). Experiments show that formation of a dry-spot in an early stage of an injection process does not necessarily lead to scrap parts. Therefore, simulation-based predictions of dry-spots are no sufficient condition for identification of unsuitable injection strategies. In this paper, the resolution mechanisms of dry-spots under controlled process conditions are investigated and the resulting findings of fundamental formation- and dispersion-mechanisms are presented.
\end{abstract}

Keywords Dry-spot · Void · Pores · Dispersion ·

Dissolution · Diffusion · Liquid composite molding · LCM

\section{Introduction}

The proportion of fiber-reinforced structures in the aviation sector rose from approximately $3 \%$ in the 1970 s (A300) to over $50 \%$ in 2011 (A350) [19]. Hence, automated and

This paper is based on a presentation at the German Aerospace Congress, September 16-18, 2014, Augsburg, Germany.

\section{Bertling}

dominic.bertling@dlr.de

1 German Aerospace Center, Institute of Composite Structures and Adaptive Systems, Lilienthalplatz 7 , 38108 Braunschweig, Germany reproducible manufacturing of complex composite structures is a subject of major effort in research and industry.

In most cases parts are made by hand layup prepreg and curing in the autoclave, but high potential of cost efficiency in the automated batch production is attributed to the use of liquid composite molding processes (LCM) [4], specially when the geometric complexity is high [14]. In this method, dry fabrics get impregnated by a liquid matrix which is injected within a mold. This process is suitable for small to large production series and enables the production of a wide variety of parts with variable degrees of complexity $[17,20]$. Due to size of aircraft components, it is common practice to enhance the infiltration by using flow media.

Particular attention is given to sandwich structures using foam cores because of a variety of advantages in the field of lightweight structure design and cost-efficient production processes. Due to the fact that most aeronautical applications require at least one smooth surface and to satisfy close geometric tolerances, there is interest to use flow channels in the foam core instead of a flow media on the rigid tool side. During the infiltration process these flow channels lead to qualitatively large dry-spots by flow front junctions as shown in Fig. 1.

Rene Arbter stated that dry-spots are separated into many small voids instead of being spilled out as a whole bubble [2]. Other studies show that mechanical properties such as shear strength, tensile strength, and flexural strength of composite parts decrease with increasing void content $[5,6,8,15,16]$. Therefore final products with more than $2 \%$ of void defects should be rejected.

However, void removal during injection of dry laminate is possible. The transport of mobile voids in the pressure field of the resin injection has a significant influence on the removal of voids [12]. Voids are removed by reaching the 


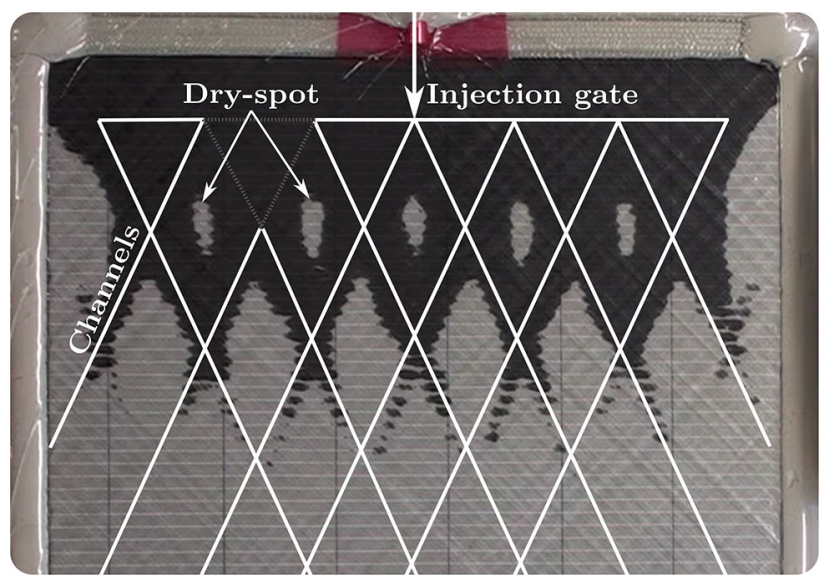

Fig. 1 Dry-spots during infiltration process

flow front, but can also remain in the cured laminate if held back by mechanical traps [7, 13]. Examples for mechanical traps are sewing threads or intersections of warps and wefts. A further possibility of void removal is the diffusion of trapped gas into the resin system [13].

If these results are applicable and dry-spots disperse into many small voids during LCM processes, the formation of a dry-spot is not necessarily a failure criterion. A flow front junction can maybe tolerated without compromising the quality of the final product. In the following sections, the resolution mechanisms of dry-spots under controlled process conditions and the resulting findings of fundamental formation- and dispersion mechanisms are presented.

\section{Initial tests}

All experiments are performed on fiberglass fabrics due to transparency of impregnated fiberglass. The refractive indexes of transparent resins and glass are similar. Nonporous laminates are almost fully transparent. However, they get a milky tint with the increase of voids. Hence, a high transparency can be used as a quality criterion [18]. In addition, online detection of voids in a fiberglass-reinforced composite can be realized optically.

Woven fiberglass fabrics are used in this analysis, even though woven fabrics in general are rarely used in the aerospace industry. However they are largely used for production of parts made by LCM processes. The main reason for woven fabrics is the higher homogeneity compared to non-crimp fabrics due to uniform distribution of warp and weft threads and the missing sewing threads. The most conventional type of weave in the aerospace industry is the twill weave, where the wefts are passed over two warps. In this analysis, the product Interglas Style 92125 is used.
To analyze the general behavior of dry-spots and to validate the experimental setup, the initial tests are performed in an open-mold $\mathrm{VAP}^{\circledR}$-process at room temperature. Therefore the fiber volume fraction may not be constant, uniform or adjustable. Open-mold processes can easily be observed, documented and are flexible for setup changes. Hence, only room temperature curing matrix systems are taken into consideration. For the pretests, the two-component epoxy system SR1710i from Composite Solutions AG with the hardener SD 8824 is used. This resin system has a low initial viscosity of $130 \pm 20 \mathrm{mPas}$ at $25^{\circ} \mathrm{C}$ compared to other room temperature curing systems, which makes it comparable to the low application viscosity of heated curing systems that are commonly used in aerospace industry. HexFlow ${ }^{\circledR}$ RTM 6 which is one of those has an initial viscosity of $33 \mathrm{mPas}$ at $120^{\circ} \mathrm{C}$.

In order to document the initial tests with a video camera, the solid mold tool has to be transparent as well. A glass plate is used as a basic tool. First the dry fabric is cut to size and placed on the glass plate. Secondly the injection gates are attached. Then the setup is sealed airtight against the ambient atmosphere with a vacuum bag. To ensure the online monitoring of the experiment, the gate area is covered with a transparent membrane. The end of the laminate is sealed with a $\mathrm{VAP}^{\circledR}$-membrane. This semipermeable membrane allows venting the cavity while serving as a barrier for the liquid resin. After sealing the first vacuum bag, a second transparent vacuum bagging is applied. The $\mathrm{VAP}^{\circledR}$-membrane enables evacuation of first bagging by evacuating the second bag.

\subsection{Experimental setup}

The infusion strategy for initial tests is presented in Fig. 2. The injection gates of the setup are separately controlled. First the infusion line and the four gates are opened, which results in a dry-spot. The amount of trapped gas in the dryspot depends on absolute evacuation pressure and the enclosed volume at time of isolation from the vacuum zone $\left(\mathrm{VAP}^{\circledR}{ }^{\circledR}\right.$-membrane).

After complete separation of the dry-spot, the four pinpoint gates are disconnected. Due to the continuously moving flow front, the pressure gradient is nearly homogeneous but not constant over time. As shown in Fig. 2, the pressure gradient depends on the distance between the flow front and the line gate which increases during the infusion progress. The observation period ends when the whole laminate is impregnated.

\subsection{Dispersion of dry-spots}

The generated dry-spot disperses into many small voids from its low pressure side during the initial tests. On the 

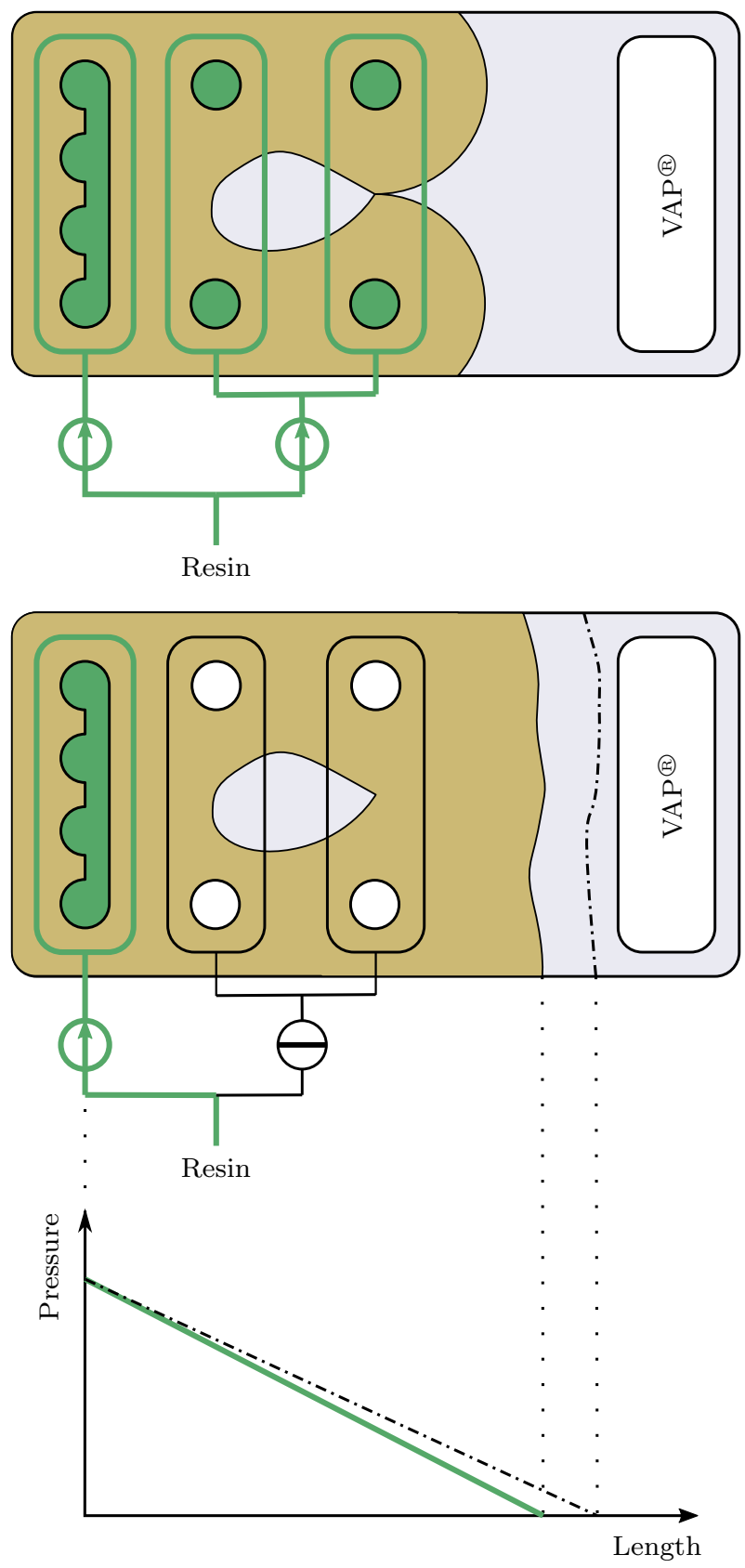

Fig. 2 Infusion strategy for initial tests

high pressure side a low velocity flow front proceeds to close the dry-spot. The generation of many small voids is related to the presence of fibers. Without fibers, the whole dry-spot would move towards the vent. Furthermore, a pulsation of the dry-spot and the void field was observed while dispersion. Figure 3 shows a series of photos of the pulsation phenomenon. It can be observed that interconnected voids grow to capillaries on their way towards the flow front while the dry-spot disperses. When the capillaries reach the flow front, the dry-spot seems to be temporarily short-circuited with the vacuum zone. However,

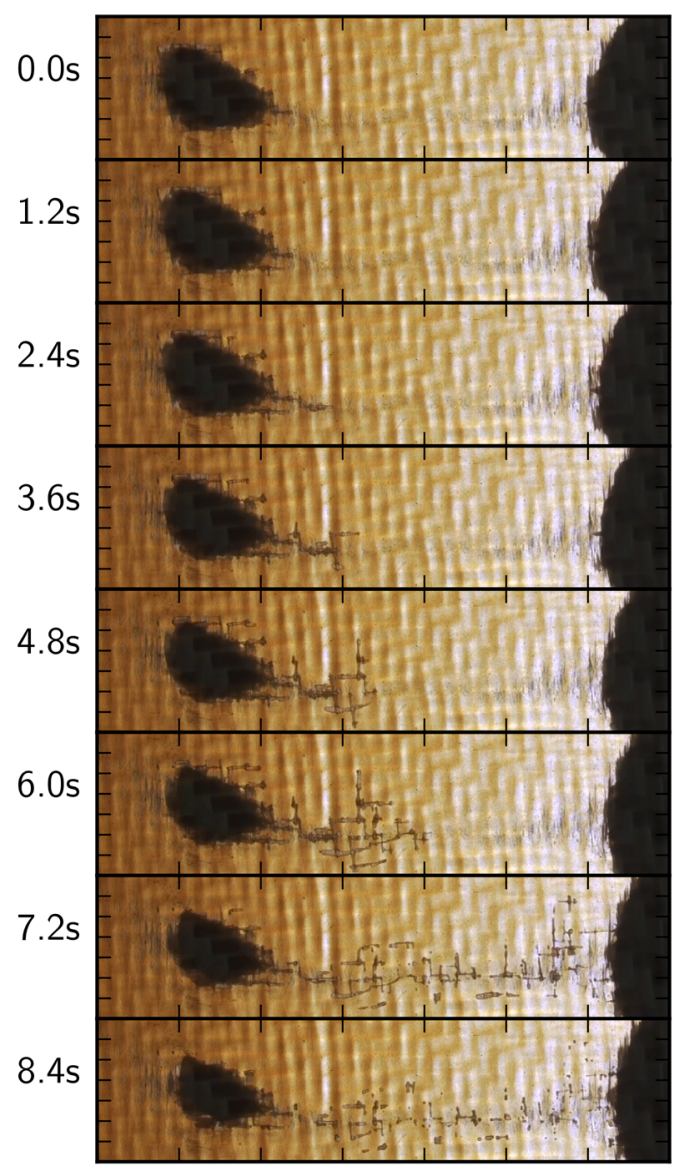

Fig. 3 Dry-spot dispersion

a)

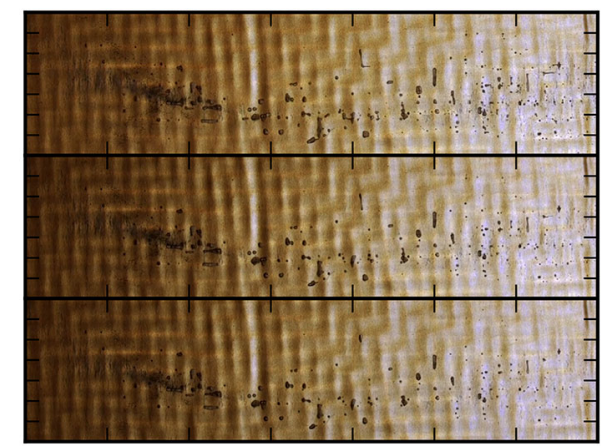

Fig. 4 Remaining void field after complete dispersion of dry-spot; the flow front is progressing outside of observed specimen

this bypass breaks immediately. The capillary network collapses and several voids remain, some of which are mobile and flowing towards the flow front. After collapse, the formation of another network starts. This phenomenon repeats, until complete dispersion of the dry-spot.

After dispersion of the dry-spot, some visible voids remain in the laminate. The images in Fig. 4 show these remaining voids. The interval between every image is $60 \mathrm{~s}$. The flow front is still progressing outside of the observed 
specimen. It is recognizable that void-number and -size decreases with time.

\subsection{Influence of fiber orientation}

Within the initial tests, different orientations of the fiberglass fabric have been tested: $\left(0_{6}\right),\left(45_{6}\right)$ and $(0 / 45 / 0 / 45 / 0 /$ $45)$.

In all tested laminates, a certain percentage of voids are mobile. In contrast, some voids remain stationary throughout the entire process. Apparently most of the stationary voids stick at the intersections of the warps and wefts while the mobile voids follow the orientation of the fabric. In the experiments with a fabric orientation of $0^{\circ}$, the voids flow in $0^{\circ}$ and $\pm 90^{\circ}$ direction. When using six layers with $\pm 45^{\circ}$ orientation, the voids move on a $45^{\circ}$ rotated raster. In a mixed layer setup, the voids flow both in the $0^{\circ}, \pm 90^{\circ}$ as well as $\pm 45^{\circ}$ direction. The detailed observation of an individual mobile void shows that it can switch its direction of movement between the $0^{\circ}, \pm 90^{\circ}$ and $\pm 45^{\circ}$ raster. Thus it follows the warp and weft directions of different layers.

The velocity of mobile voids in all experiments is significantly higher than the flow front velocity. As shown in Fig. 5 the void disturbs the pressure distribution and according to Darcy's law the resulting high-pressure gradients lead to high flow velocities. The fast flowing resin in front of the void clears the way and the resin behind the void fills the empty area. [2] A movement against flow direction of the resin system was not observed. The mobile voids flow in the direction of pressure gradient, along the warps and wefts towards flow front.

Subjectively, more voids remain stationary in the $0^{\circ}$ layer stack compared to the $+45^{\circ}$ orientation. A quantitative analysis has not been performed.

That voids are most likely to be washed out along the fabric directions is related to the textile architecture. As sketched in Fig. 6 the local fiber volume content $\left(V_{\mathrm{f}}\right)$ in

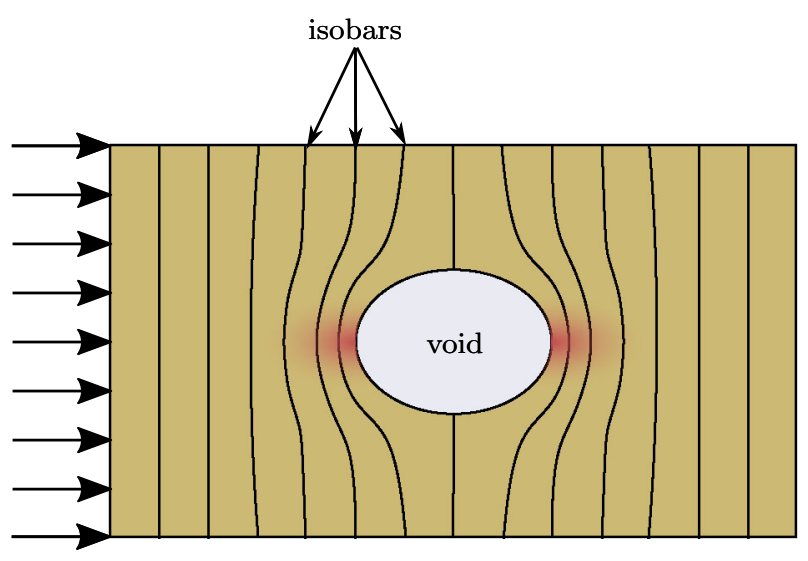

Fig. 5 Pressure distribution in flow channels with void [2]
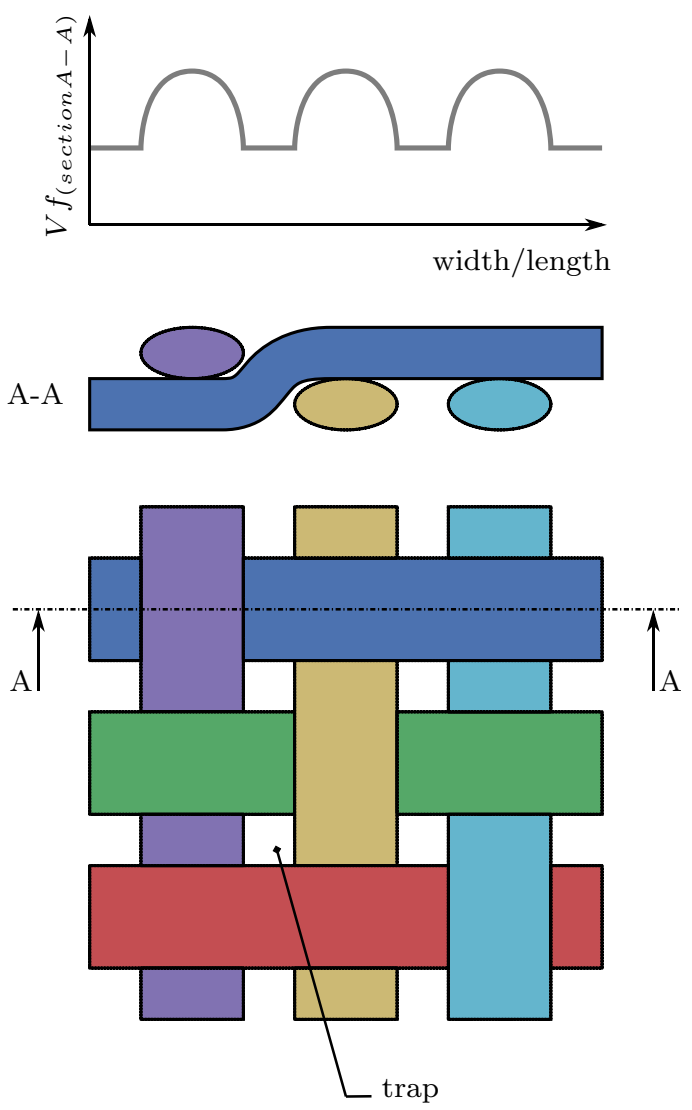

Fig. 6 Sketch of local fiber volume fraction $\left(V_{\mathrm{f}}\right)$ for used twill weave

warp- and weft-direction is minimum in inter-fiber gaps. Hence, the permeability is maximum where the fiber volume content is minimum, the highest flow velocities occur between the tows. Another reason is the surface tension of the fluid which makes the void acquire the least surface area possible. Therefore, surface tension gives the void a near-spherical shape because a spherical shape has the smallest possible surface area to volume ratio. Hence, the enclosed gas tends to locate as biggest possible void in places of low fiber volume content.

Stationary or partially trapped voids are related to surface tension as well. As mentioned before, enclosed gas tends to locate as biggest possible near-spherical voids to minimize wall tension. This happens between four fiber cross-over points, marked as 'trap' in Fig. 6. To proceed its way to the vent a trapped void needs to change its energy saving shape to pass the blocking warp- or weft-tow. While moving from high to low pressure the void expands which impedes its flow.

\subsection{Influence of diffusion}

Multiple studies show that voids can decrease in size or dissolve completely due to diffusion of gaseous components into the resin system. The reduced size of stationary 


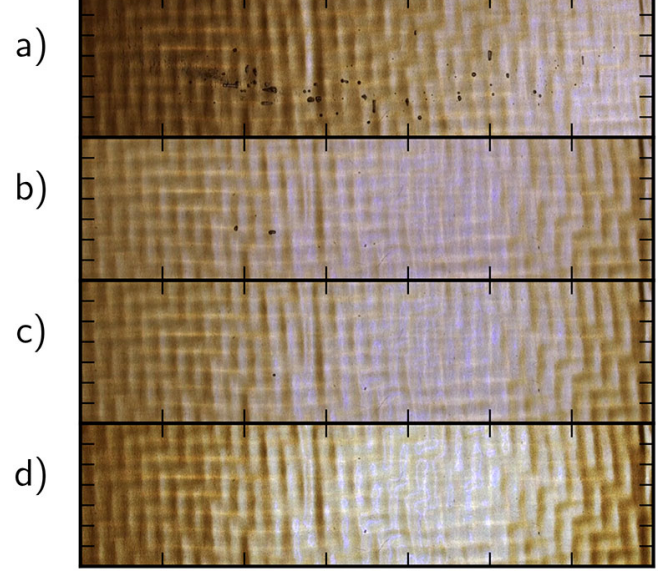

Fig. 7 Void field during curing of laminate; the flow front is progressing outside of observed specimen till collapse due to curing resin

voids will increase the probability to become mobile. Thus voids are able to reach the flow front and vanish from the laminate. [9-11, 22, 23]

For a qualitative proof of the diffusion effect, the remaining void field has been observed till complete cure. Figure 7 shows images of the void field at an interval of 20 min. The line injection gate is kept open during the entire experiment, and the flow front is progressing outside of the observed specimen till collapse due to curing resin. No mobile voids have been observed in the course of the four images. The last few dark pixels that seem to be voids in image $\mathrm{d}$ are dust particles which fell onto the experimental setup during injection. The demolded part was apparently free of voids.

Diffusion of gaseous components of the voids into resin is assumed to be the reason for dissolution of the voids. The resin flows around the voids and acts like a transport medium which steadily removes gaseous fractions from the void. An additional initial test without resin flow is performed to prove if the presence of resin flow has an effect on the dissolution of voids, therefore an open-mold singleline injetion process (SLI) with ring gate is used to trap a similar amount of gas. Figure 8 illustrates the experimental setup. Firstly, the ring gate is used to evacuate the dry laminate. Secondly, the vacuum pump is separated from the laminate and the ring gate is connected with the resin pot.

Figure 9 shows the experiment directly after forming of the dry-spot and $65 \mathrm{~min}$ later. The diffusion rate seems to be dependent on the resin flow. In case of ring injection, the resin flow stops straight after the formation of the dry-spot. The concentration difference between included gas and bordering resin decreases with progressing diffusion and void size decreases slightly. One can see clearly that the
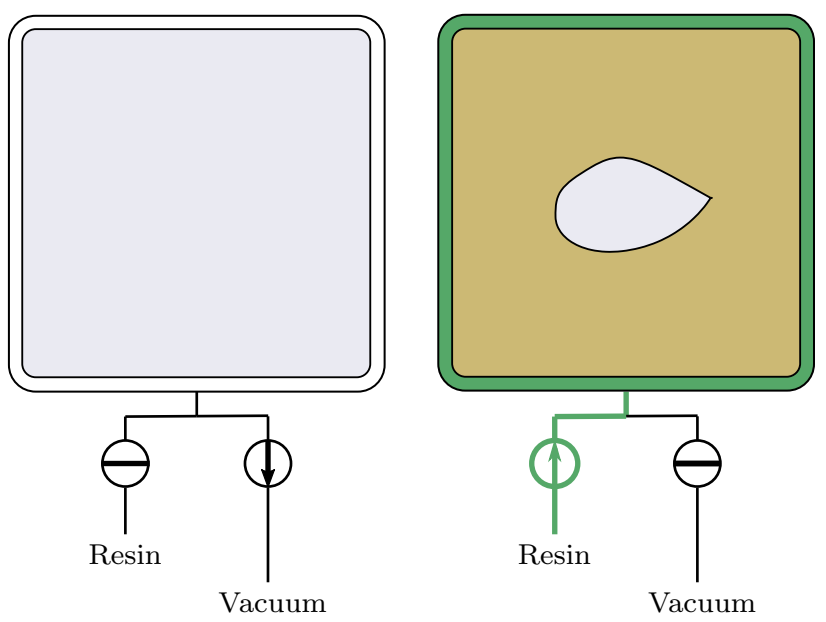

Fig. 8 SLI-process with ring gate to trap a dry-spot

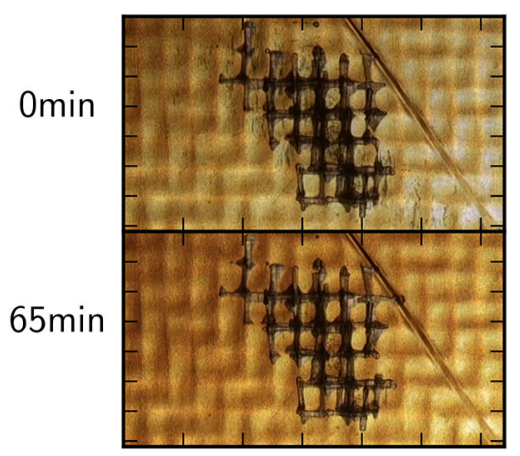

Fig. 9 Dry-spot development without resin flow

trapped gas fills regions of low fiber volume content as mentioned in Sect. 2.3.

If the flowing resin system passes the void or dry-spot, the trapped gas stays continuously in contact with fresh resin. The concentration difference between the voids and the flowing resin remains maximum over the whole injection duration, thus the diffusive transport capacity by the dissolution of gaseous components into the resin is maximum as well.

\section{Influence of injection parameters}

In order to reduce the complexity of parameter interactions, the experimental setup is changed from open to closed mold. In this case, the local fiber volume content is constant during injection and can be mechanically adjusted by the cavity height. To control the leading parameters, the experimental and process setup is developed in the form of a vacuum-assisted resin transfer molding tool (Fig. 10).

Moreover, the injection concept is designed to maintain a homogeneous and temporally constant global pressure gradient after the formation of dry-spot. This is achieved 


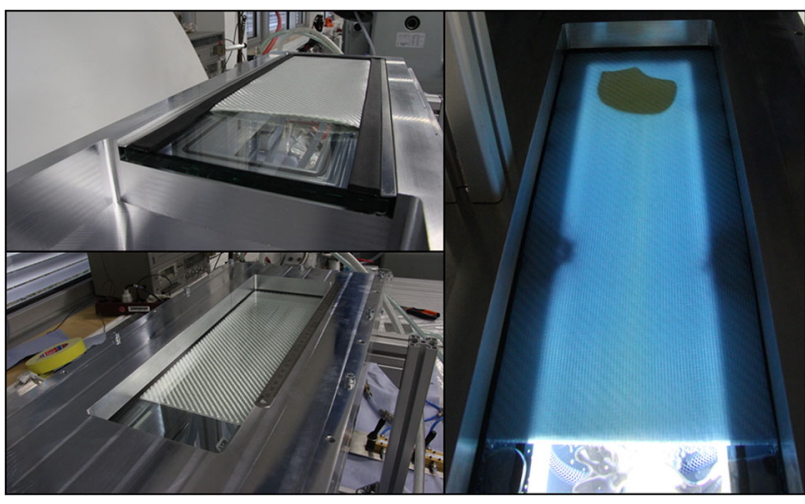

Fig. 10 Test tool/experimental setup

by creation of a saturated flow setup before dry-spot generation, i.e., the flow front reaches the vent before generation of the dry-spot. Figure 11 shows the optimized injection strategy and the necessary injection steps.

In order to avoid viscosity changes by various process temperatures (e.g., heat radiation from lighting) and reaction processes of the resin, a replacement liquid is chosen. The viscosity of silicone oil can be presumed as constant regarding small temperature variations. Silicone oil has Newtonian properties and is not subjected to viscosity changes concerning reaction processes. Therefore it is recommended for permeability measurements [21]. Silicone oils of different viscosity from ELBESIL are chosen. For the experiments, the oil is colored with $1 \frac{\mathrm{mg}}{1}$ EpoBlue, which results in a higher contrast between the dry-spot and the otherwise colorless silicone oil.

Table 1 displays the experimental parameters and their dependencies for the test setup.

\subsection{Experimental result analysis}

Void growth to capillaries as explained in Sect. 2.2 is observed in the closed mold experiments as well. Due to worse contrast between voids and the colored silicone oil interconnected voids and capillaries are poorly visible. If the dry-spot is temporarily short-circuited with the vent, it is not observable by the rigid tooling. However, the distance between the dry-spot and flow front is approximately $250 \mathrm{~mm}$ and the pulsation phenomenon can be monitored. The results in Figs. 13, 14 and 16 show clearly that the dissolution of a dry-sport is subjected to pulsation.

The starting time of void movement is determined manually by analyzing the video record. It is examined on two characteristics: firstly, if the front half of the phase boundary between dry-spot and fluid remains stationary until the spot gets dispersed; secondly, if a slight diffuse boundary between fluid and gas exists. Figure 12 shows both phenomena.

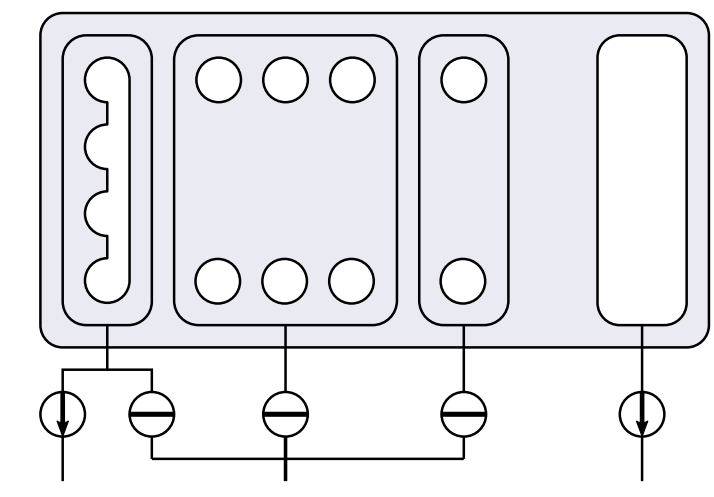

Vacuum Resin

Resin trap

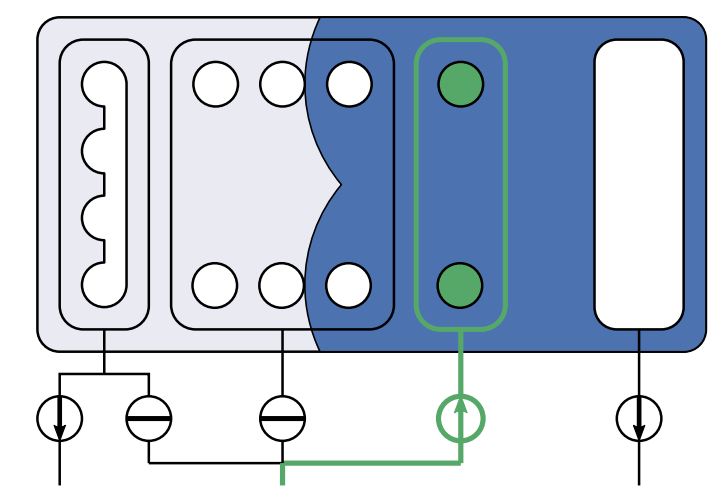

Vacuum Resin

Resin trap

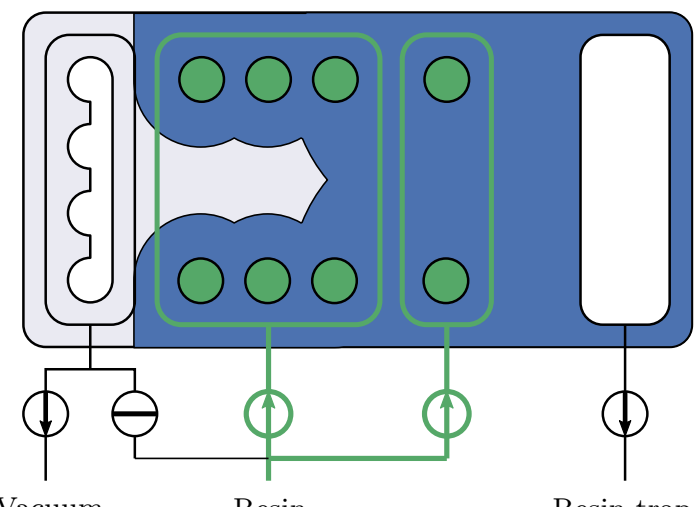

Vacuum Resin Resin trap

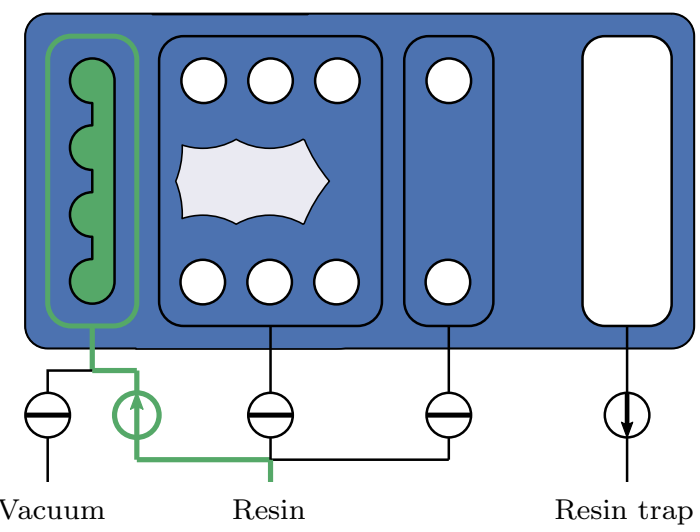

Fig. 11 Injection strategy and necessary injection steps 
Table 1 Test parameters and their dependencies

\begin{tabular}{ll}
\hline Parameter & Dependencies \\
\hline Dry-spot size & $\begin{array}{c}\text { Venting pressure, fiber volume content, flow } \\
\text { front geometry, injection concept }\end{array}$ \\
Viscosity & Temperature, fluid \\
Global pressure & $\begin{array}{c}\text { Injection pressure, venting pressure, distance } \\
\text { gradient }\end{array}$ \\
Permeability & flow front/injection gate
\end{tabular}

Fig. 12 Phase boundary dryspot

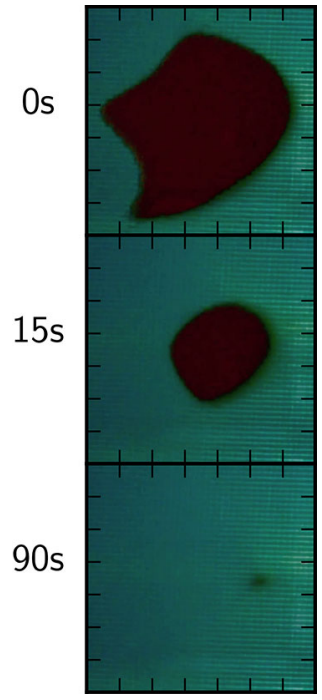

Starting from the identified time, the dry-spot area is measured with the open source image processing and analyzing software ImageJ [1].

\subsection{Size of the dry-spot}

The size of the dry-spot is affected by the flow front geometry, the fiber volume content and the absolute evacuation pressure. The flow front geometry itself is determined by the fabrics permeability tensor and the injection strategy of the tool. A change in the fiber volume content would also change its permeability. Therefore, within the series of experiments, the amount of trapped gas has to be set to vary the size of dry-spot. Hence the absolute evacuation pressure has to be adjusted before the dry-spot occurs.

As featured in Fig. 12, the boundary between fluid and gas on the low pressure side remains stationary until complete dispersion of the dry-spot, even under variation of the enclosed mass. Due to the injection strategy, the boundary between fluid and dry-spot is kept nearly at the same position for all experiments. Moreover, the pressure gradient between injection and venting point is constant in each test. As a result, a large dry-spot forms and locates

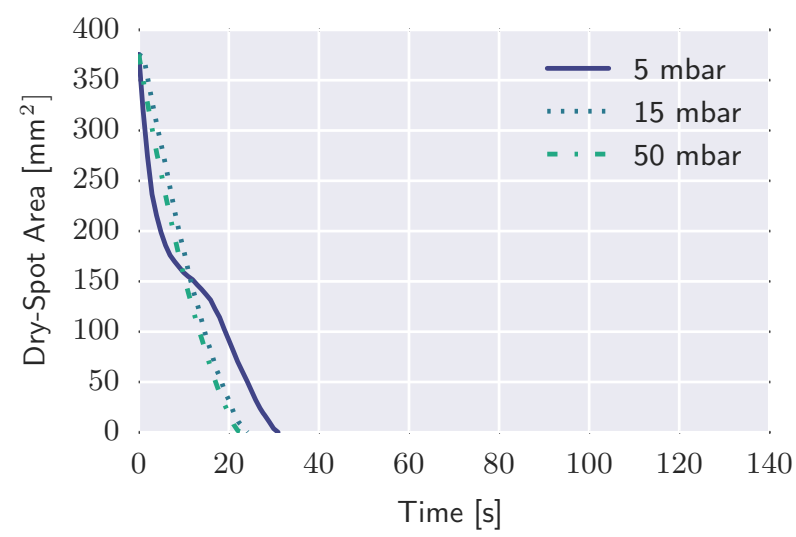

Fig. 13 Dry-spot area versus time for different initial dry-spot sizes

itself with time, similar to that of a small dry-spot at measurement start.

Consequently, the measured graphs with lower absolute evacuation pressure represent sections of the graphs with higher absolute evacuation pressure. The initial dry-spot size has no effect on the size-dependent areal diminishment.

Figure 13 shows the results of the experiments. The graph for an evacuation pressure of 5 mbar crosses the other curves due to the fact that the pulsation phenomenon (explained in Sect. 2.2) took place. Further process parameters are: 8 plies with a cavity height of $2 \mathrm{~mm}$, absolute injection pressure of 1 bar and a fluid viscosity of $100 \mathrm{cSt}$.

\subsection{Fluid viscosity}

The fluid viscosity is depending on the used silicone oil and oil temperature. Therefore, different silicone oils are used for viscosity variation. A direct comparison of results shows that the dispersion speed of a dry-spot decreases with increasing viscosity. With higher viscosity, the time of complete dispersion is delayed (Fig. 14). Further process parameters are: 8 plies with a cavity height of $2 \mathrm{~mm}$, absolute injection pressure of 1 bar and absolute evacuation pressure of 5 mbar.

\subsection{Pressure gradient}

The pressure gradient is the quotient of the pressure difference between injection and venting gate and the wetted fabrics length. Hence, it depends on the absolute injection pressure, the absolute evacuation pressure and the length of the laminate. The used fiber material has a length of $300 \mathrm{~mm}$ in all experiments. To vary the pressure gradient, different absolute injection pressures are used. Further process parameters are: 8 plies with a cavity height of $2 \mathrm{~mm}$ and fluid viscosity of $100 \mathrm{cSt}$. 


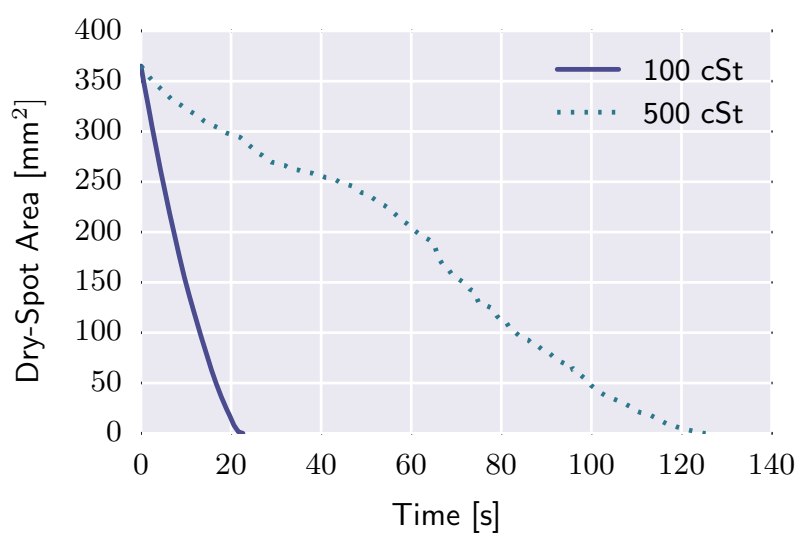

Fig. 14 Dry-spot area versus time for different fluid viscosities

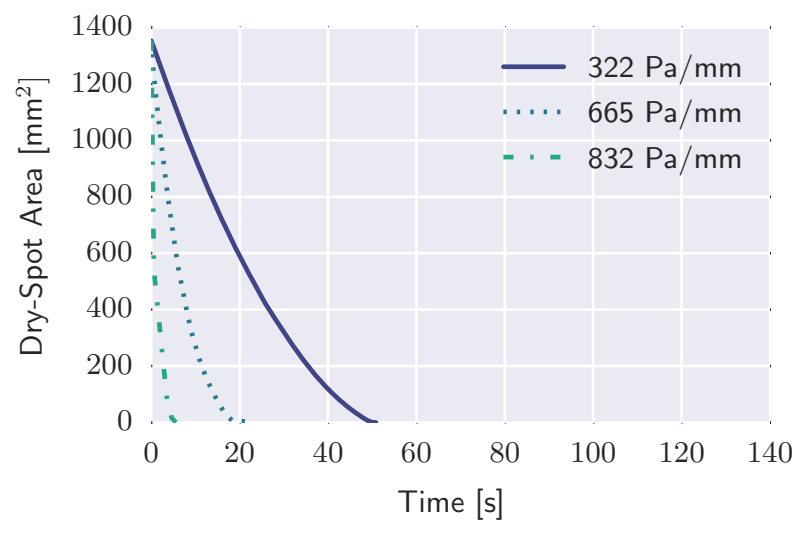

Fig. 15 Dry-spot area versus time for different pressure gradients

Figure 15 shows the gathered data. The complete dispersion of dry-spots is achieved faster with a higher pressure gradient. The areal diminishment increases with increasing pressure gradient.

\subsection{Permeability}

The permeability depends on the used fabric and fiber volume content of the laminate. Therefore, permeability variation is achieved by changing the amount of fiberglass plies in the closed mold tool which leads to a varied fiber volume content.

The effective permeability in major and minor flow direction is determined by picture analysis based on Darcy's law as mentioned by Chan et al. [3]. A picture sequence of the first injection step is used for measurement. As the flow front boundary is circular in shape, the permeability in major and minor flow direction is equal.

The comparison of the recorded data shows, that the diminishment of the dry-spot area decreases with decreasing permeability. Hence, the complete dispersion of dry-spots at low permeability is delayed (Fig. 16). Further process parameters are: absolute evacuation pressure 5 mbar and fluid viscosity $100 \mathrm{cSt}$.

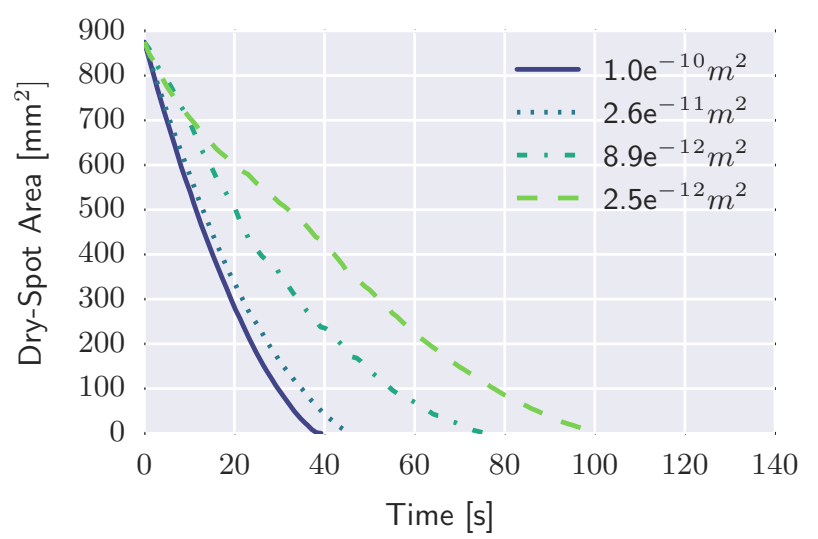

Fig. 16 Dry-spot area versus time for different permeabilities

\section{Discussion and outlook}

The experiments showed that under certain circumstances the formation of a dry-spot is not necessarily a failure criterion for an injection concept, as the dry-spot can disperse under certain conditions.

Parameters that have an influence on the diminishing rate of dry-spots have been identified and correspond to Darcy's law: the viscosity of the matrix system, the pressure gradient and the fabrics permeability. In conclusion, the following statements could be made:

- Removal of dry-spots is driven by resin flow into the dry-spot

- Removal of dry-spots takes place as dispersion of the dry-spot and removal of voids

- Dry-spots can disperse completely during a proceeding injection process

- Mobile voids are removed by reaching the flow front

- Voids partially get trapped

- Trapped voids can dissolve completely due to diffusion of gaseous components into the resin

Future work aims to archive detailed and accurate understanding of the interaction between each of the parameters. This enables quantitative statements about the impact of dry-spots in LCM-simulations.

Acknowledgments This work was supported by the German Federal Ministry for Economic Affairs and Energy (Grant 20W1306B) under research program of 'LuFo V'. Special thanks goes to Nico Liebers for the quality of his technical support.

Open Access This article is distributed under the terms of the Creative Commons Attribution 4.0 International License (http://crea tivecommons.org/licenses/by/4.0/), which permits unrestricted use, distribution, and reproduction in any medium, provided you give appropriate credit to the original author(s) and the source, provide a link to the Creative Commons license, and indicate if changes were made. 


\section{References}

1. Abràmoff, M.D., Magalhães, P.J., Ram, S.J.: Image processing with imagej. Biophotonics international 11(7), 36-42 (2004). http://www.imagescience.org/meijering/publications/download/ bio2004.pdf

2. Arbter, R.: Contribution to robust resin transfer molding. Ph.D. thesis, Diss., Eidgenössische Technische Hochschule ETH Zürich, Nr. 18108, 2008 (2008). doi:10.3929/ethz-a-005730612

3. Chan, A.W., Hwang, S.T.: Anisotropic in-plane permeability of fabric media. Polym. Eng. Sci. 31(16), 1233-1239 (1991). doi:10. 1002/pen.760311613

4. Cherif, C.: Textile Werkstoffe für den Leichtbau. Springer (2011). doi:10.1007/978-3-642-17992-1

5. Feldgoise, S., Foley, M., Martin, D., Bohan, J.: The effect of microvoid content on composite shear strength. In: International SAMPE Technical Conference, 23 rd, Kiamesha Lake, NY, pp. 259-273 (1991)

6. Ghiorse, S.: Effect of void content on the mechanical properties of carbon/epoxy laminates. SAMPE quarterly 24(2), 54-59 (1993). http://adsabs.harvard.edu/abs/1993SAMPQ..24...54G

7. Hayward, J., Harris, B.: The effect of vacuum assistance in resin transfer moulding. Compos. Manuf. 1(3), 161-166 (1990). doi:10.1016/0956-7143(90)90163-Q

8. Judd, N.C.W., Wright, W.W.: Voids and their effects on the mechanical properties of composites-an appraisal. Sampe J 14, 10-14 (1978)

9. Kardos, J., Dave, R., Duduković, M.: Voids in composites. In: ASME Manufacturing International. Atlanta (1988)

10. Kardos, J., Duduković, M., Dave, R.: Void growth and resin transport during processing of thermosetting matrix composites. In: Epoxy resins and composites IV, pp. 101-123. Springer (1986). doi:10.1007/3-540-16423-5_13

11. Lundström, T.S.: Measurement of void collapse during resin transfer moulding. Compos. Part A Appl. Sci. Manuf. 28(3), 201-214 (1997). doi:10.1016/S1359-835X(96)00109-1

12. Lundström, T.S., Frishfelds, V., Jakovics, A.: Bubble formation and motion in non-crimp fabrics with perturbed bundle geometry.
Compos. Part A Appl. Sci. Manuf. 41(1), 83-92 (2010). doi:10. 1016/j.compositesa.2009.05.012

13. Lundström, T.S., Gebart, B.R.: Influence from process parameters on void formation in resin transfer molding. Polym. Compos. 15(1), 25-33 (1994). doi:10.1002/pc.750150105

14. Parnas, R.S.: Liquid Composite Molding. Carl Hanser Verlag GmbH Co KG (2000). doi:10.3139/9783446443020

15. Patel, N., Lee, L.J.: Modeling of void formation and removal in liquid composite molding. Part ii: Model development and implementation. Polym. Compos. 17(1), 104-114 (1996). doi:10. 1002/pc. 10595

16. Patel, N., Rohatgi, V., Lee, L.J.: Influence of processing and material variables on resin-fiber interface in liquid composite molding. Polym. Compos. 14(2), 161-172 (1993). doi:10.1002/ pc. 750140210

17. Potter, K.: The early history of the resin transfer moulding process for aerospace applications. Compos. Part A Appl. Sci. Manuf. 30(5), 619-621 (1999). doi:10.1016/S1359-835X(98) 00179-1

18. Schürmann, H.: Konstruieren mit Faser-Kunststoff-Verbunden. Springer (2005). doi:10.1007/978-3-540-72190-1

19. Schwarz, P.: Begrüßung zum 1. Augsburger ProduktionstechnikKolloquium, Premium AEROTEC GmbH (2011)

20. Unknown: Vom Schwer- zum Leichtgewicht: LKW-Fahrerkabine leichter durch Faserverbundwerkstoff. K-Zeitung (1999)

21. Vernet, N., Ruiz, E., Advani, S., Alms, J., Aubert, M., Barburski, M., Barari, B., Beraud, J., Berg, D., Correia, N., et al.: Experimental determination of the permeability of engineering textiles: Benchmark ii. Compos. Part A Appl. Sci. Manuf. 61, 172-184 (2014). doi:10.1016/j.compositesa.2014.02.010

22. Wood, J.R., Bader, M.G.: Void control for polymer-matrix composites (1): theoretical and experimental methods for determining the growth and collapse of gas bubbles. Compos. Manuf. 5(3), 139-147 (1994). doi:10.1016/0956-7143(94)90023-X

23. Zingraff, L., Michaud, V., Bourban, P.E., Månson, J.A.: Resin transfer moulding of anionically polymerised polyamide 12 . Compos. Part A Appl. Sci. Manuf. 36(12), 1675-1686 (2005). doi:10.1016/j.compositesa.2005.03.023 